\title{
HAEMODIALYSIS
}

\section{Indications and Results}

\author{
By F. M. Parsons, B.Sc., M.B., Сн.B. \\ Assistant Director, Metabolic Disturbances in Surgery, M.R.C. Unit, the General Infirmary at Leeds
}

Although Abel, Rowntree and Turner (1913) devised an artificial kidney, Kolff and Berk (1943) designed the first practical machine. Kolff used heparin as an anticoagulent and blood circulated through a cellophane tube, which was wound round a drum rotating in a dialysing fluid. The Peter Bent Brigham Hospital (Murphy et al., 1952) improved this machine by making it of stainless steel and introducing non-wettable plastic surfaces for carrying the blood to and from the cellophane tube which enabled the dose of anticoagulent to be reduced to safe levels. Since 1943 other types of artificial kidney have been introduced and in some the blood circulates under pressure so that ultrafiltration as well as dialysis occurs (Alwall, 1947; Skeggs and Leonards, I948; and the twin-coil of Kolff and Watschinger, 1956). The present day machine is quite safe and little, if any, haemolysis occurs.

In this country, we have been slow to appreciate the value of these machines. This has probably been due to an over-enthusiastic appraisal of the dietary regime used in patients with acute renal failure. Further experience has revealed that a considerable number of these patients have very protracted periods of oliguria and others develop uraemia very early. In these and other situations haemodialysis, when used correctly, can prolong life until renal function recovers.

\section{Description of the Procedure}

The procedure differs slightly according to the type of machine that is used. Cellophane, which is common to all, is a semi-permeable membrane which has a fractional pore area of 30 to 45 per cent., a pore radius of $3 \circ \mathrm{A}^{\circ}$ and a pore length of $80 \mu$ (Merrill, 1955). The pores are too small to allow plasma proteins to pass through and hence, during the period of haemodialysis, neither will viruses or bacteria so that the dialysing fluid need not be sterile. In most machines the blood travels through the lumen of a cellophane tube which is placed in the dialysing fluid. The rest of the machine is concerned with transporting blood to and from the patient. Coagulation of blood is delayed by giving $100 \mathrm{mg}$. of heparin at the start of the dialysis and ro mg. hourly.
Before starting the dialysis one to two pints of citrated blood are used to prime the machine. The flow rate of blood through the dialyser varies from 200 to $500 \mathrm{ml} . / \mathrm{min}$. according to the type of machine.

The dialysis usually lasts six hours. Two medical and two nursing personnel, trained in the procedure are required. Bio-chemical investigations are sometimes essential. The procedure is not unduly trying for the patient but sedatives should be avoided as they often have adverse effects in a uraemic patient.

\section{Function of the Machine}

It is surprising that little is known about the function of these machines although they have been in use for 16 years. Also there is no firm agreement as to how far the uraemic state should be improved during one dialysis, indeed many authors seem satisfied if the final blood urea is as high as $150 \mathrm{mg}$. per cent. Our own experience suggests that none of the present-day machines are adequate to satisfy all the exacting demands of clinical practice.

Wolf et al. (1950) performed some clearance studies with the Kolff-Brigham machine. They showed that the clearance of substances depended on the flow rate, the nature of the chemical substance, and the diffusion gradient across the cellophane membrane. Substances such as urea and potassium were cleared relatively fast, whilst others, such as phosphate, were cleared very much more slowly. The clearance of non-electrolytes decreased as the molecular weight increased but other factors, such as electrical charges, could adversely effect the clearance of electrolytes.

Using the same machine we repeated these experiments (Fig.) but increased the dialysing surface area from 2.2 to $2.8 \mathrm{sq}$. $\mathrm{m}$. and the flow rate was increased from 500 to $\mathrm{I}, 000 \mathrm{ml}$./min. (Parsons and McCracken, 1958). The maximum clearance for urea was not reached at a flow rate of 1,000 $\mathrm{ml}$./min., for creatinine it was reached at about $500 \mathrm{ml} . / \mathrm{min}$., whilst for phosphate it was about $300 \mathrm{ml} . / \mathrm{min}$. Other experiments showed that increasing the dialysing surface area from 2.2 to 2.8 sq. $\mathrm{m}$. improved the clearance of urea and 


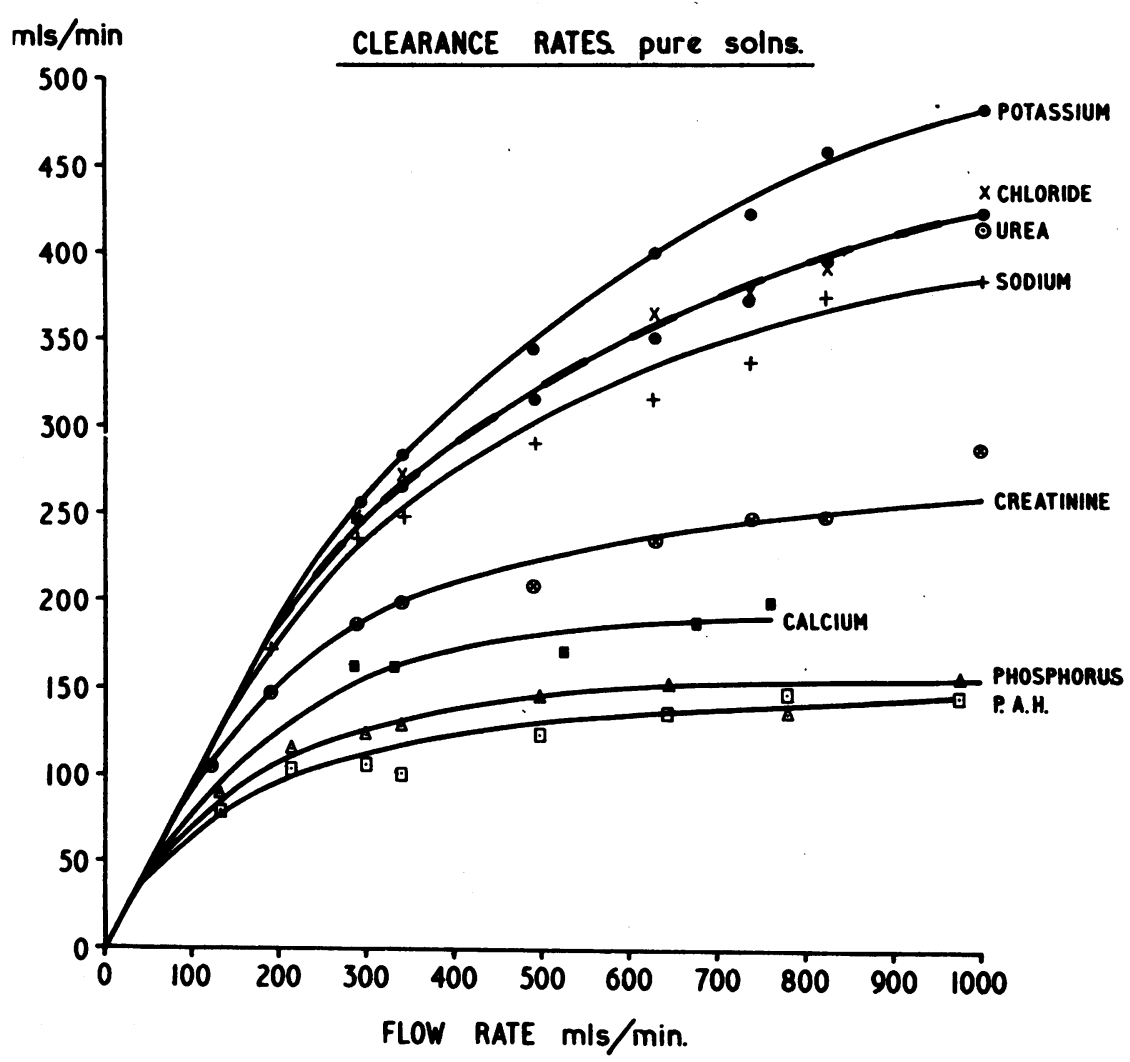

creatinine provided the flow rate was increased from 300 to 400 or $500 \mathrm{ml}$./min. On the other hand the clearance of phosphate was improved by increasing the dialysing surface area to $2.8 \mathrm{sq}$. $\mathrm{m}$. but was not affected by flow rate greater than $300 \mathrm{ml} . / \mathrm{min}$.

These results were obtained with pure solutions. In clinical use blood is circulating through the machine and some substances are probably removed only from the plasma and not from the red cells. Until more is known about this aspect it is suggested that for optimum efficiency a plasma flow rate of $300 \mathrm{ml} . / \mathrm{min}$. is desirable in a machine that has a dialysing surface area of 2.8 to $3.2 \mathrm{sq} . \mathrm{m}$.

During a six hours' dialysis even the larger machine, which is in use in our department, will not correct completely a uraemic state. Although some substances, e.g. urea, can be removed fairly completely from the total body water other substances, e.g. phosphates, are released from the cells slowly and after the dialysis the plasma level rises as redistribution occurs.

\section{Management of Patients}

Although the procedure has been used successfully to remove dialysable poisons (Kyle, Jeghers, Walsh, Doolan, Wishinsky and Pallotta, 1953;
Doolan, Walsh, Kyle and Wishinsky, $195 \frac{0}{1-3}$ Danzig, 1955; Merrill and Weller, 1952), its main use has been in the management of patients with renal failure.

\section{Acute Reversible Renal Failure*}

Anuric Phase. The basic treatment of this $\overrightarrow{\vec{A}}$ condition is dietary which must maintain normal hydration and reduce protein metabolism maximally. At the present time there is no firm agreement as to the most suitable diet. The water requirement should be considered first. Merrill (1955) pointed out that part of the insensible loss of water (about I 1./day) is replaced by the water of metabolism. He advocated a water intake of $400 \mathrm{ml}$./day but preferred to adjust the fluid intake to achieve a daily weight loss of 300 to $400 \mathrm{~g}$. We would agree and have found that a daily water intake of 600 to $800 \mathrm{ml}$. leads to over-hydration which can have serious consequences. If the water intake is too high vomiting occurs early and this has led some workers to give parenteral fluids unnecessarily.

*This term is preferred to tubular necrosis, lower nephron nephrosis, etc., and the word reversible has been added to avoid confusion with some other acute medical conditions causing complete, or irreversible renal damage. 
A water intake of only $400 \mathrm{ml}$./day considerably limits the calorie intake but it must be clearly understood that there is no experimental evidence that a high carbohydrate and fat intake can, on its own, reduce protein catabolism to low levels in a patient with acute renal failure. Merrill (1955) reiterates the need to give $100 \mathrm{~g}$. of glucose per day to prevent the ketosis caused by incomplete oxidation of fat. No harm is done if more glucose is given although $200 \mathrm{~g}$. is about the maximum when the fluid intake is $400 \mathrm{ml}$. Many authors have advocated giving $5^{\circ}$ per cent. glucose by slow intravenous infusion through a plastic tube threaded through a peripheral vein so that the tip reaches a vein of large calibre. The dangers have not been duly stressed. Three of our patients have developed severe local infection and one died from septicaemia. In another three patients the cannula eroded through an abdominal vein and entered the peritoneal cavity, one died from haemorrhage. Occasionally we have witnessed reactive oedema of the upper arm and shoulder when the tube has been inserted into an antecubital vein. Finally, large thrombi have been found adherent to the tube and wall of the vein at autopsy. Although the procedure has been used with apparent safety in many other patients, this list of complications compels us to reserve it for those patients who cannot be fed by mouth on account of gastro-intestinal lesions.

Until it is shown that a calorie intake greater than that contained in $100 \mathrm{~g}$. of glucose will significantly reduce protein catabolism we are content to give $400 \mathrm{ml}$. of 25 per cent. glucose per day by mouth with an adequate vitamin intake. Oral feeding is much appreciated by the patient. It is simple and natural. It is well tolerated even by patients in advanced uraemia.

The use of an indwelling catheter in the bladder, except for diagnostic purposes, must be condemned. Catheters invite renal infection and are a discomfort to the patient.

Recovery phase. When renal function commences to return the regime has to be altered, although it is wise not to give protein until the blood urea level falls. The volume of urine passed must be replaced as must the renal loss of $\mathrm{Na}, \mathrm{Cl}$ and $\mathrm{K}$ (once hyperkalaemia has been corrected). As soon as the blood urea level falls protein feeding should commence and, as the majority of patients are unable to take solid food, milk is the most suitable food and I 1./day should be given as soon as possible (this gives an approximate intake of $22 \mathrm{~m}$.Eq. of $\mathrm{Na}$ and $4 \mathrm{I} \mathrm{m}$.Eq. of $\mathrm{K}$, calculated from McCance and Widdowson, I946). Should vomiting occur as a result of increasing the fluid intake, water has to be given parenterally, but the oral intake of milk must be maintained.
This insistence on early feeding is designed primarily to improve the resistance of a patient as dietary deficiencies commonly occur during the anuric phase.

The maximum 24-hour volume of urine during the recovery phase is usually an expression of the state of hydration of the patient. It will be low in the presence of dehydration and high in overhydration. In a normally hydrated patient the fluid intake must be increased during the recovery phase in order to obtain a satisfactory urine output. The maximum urine output in our patients has been 2.5 to $3.51 . / 24$ hours. Occasionally it is much higher and in one of our patients, recovering from multiple injuries, it reached 121 . per day. This level was not affected by the administration of anti-diuretic hormone.

\section{Other Types of Renal Lesion}

When haemodialysis is used in other types of renal failure an accurate fluid balance must be maintained but the calorie intake has to be varied according to individual circumstances. In particular the protein intake must be adjusted to prevent worsening of the uraemic state. When the calorie intake is below basal requirements the patients should still lose weight. In patients with chronic renal disease the use of anabolic steroids may help to control the uraemia (Gj申rup and Thaysen, 1958).

\section{Indications for Haemodialysis}

The artificial kidney has not altered the basic management of patients with renal failure, rather its use is confined to the correction of advanced uraemia which is endangering life in patients whose renal function is expected to improve. In chronic renal disease the indications are less clear except when intercurrent disease, such as infection or surgery, has so increased protein metabolism as to cause severe uraemia.

Analysis of our records has revealed two important findings. Firstly, the blood chemical changes are not necessarily a reliable index of an impending catastrophe and secondly, when uraemia is allowed to progress too far protein catabolism increases at an alarming rate. This excessive catabolism has only been halted by repeating the dialysis 24 hours later.

As we have been unable to find an infallible indication for performing a dialysis we usually rely on certain changes which occur before serious complications arise. The clinical changes that indicate the correct time to dialyse include mental dullness, disorientation, unco-operation and uraemic vomiting. When uraemic twitchings, convulsions, semi-coma or an acidotic type of 
TABLE I

The Number of Patients Treated

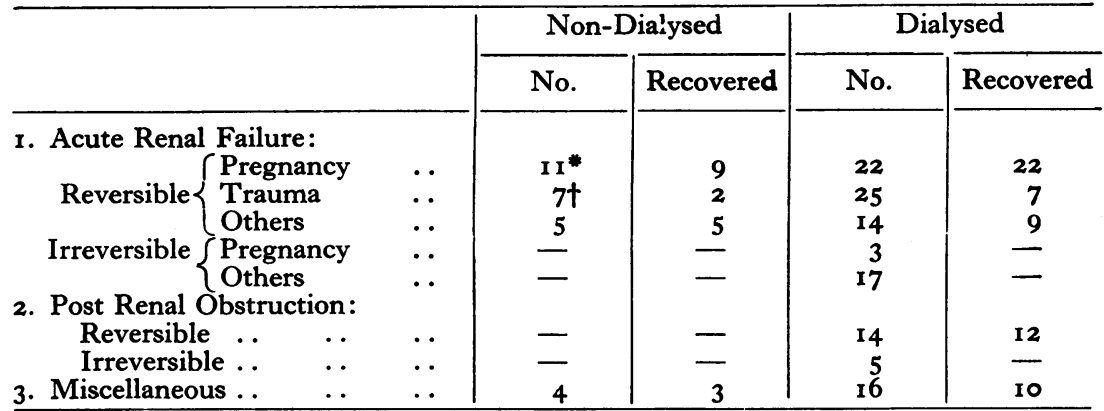

-Includes one patient who died 30 mins. after admission.

tIncludes five patients who died before a dialysis could be attempted.

respiration occur the optimum time for dialysis has passed.

The chemical changes are a little more definite although if none are present when clinical deterioration has occurred a dialysis should be performed.

Acidosis. $\mathrm{CO}_{2}$ combining power less than I3 m.Eq./1. we have usually regarded as an absolute indication.

Potassium. A serum potassium level in excess of $7 \mathrm{~m}$.Eq./1. should be treated by dialysis. When the level is rising out of proportion to the other chemical indices it is probably safe to use ion exchange resins.

Urea. Although urea is to be regarded as a non-toxic substance it does serve to indicate the amount of protein that has been metabolised. The majority of patients require a dialysis on clinical grounds when the B.U.N. has reached I 80 to $200 \mathrm{mg}$. per cent. If the clinical condition is satisfactory we do not dialyse even though the B.U.N. may rise to $250 \mathrm{mg}$. per cent., a situation most commonly seen in children.

We regard each of these chemical findings as an indication in its own right. If these indications occur when renal function is recovering additional information is required before deciding whether a dialysis is necessary. The most important is the rate of protein catabolism. If this is moderate or severe and renal function has not recovered sufficiently to prevent worsening of the biochemical state then a dialysis should be performed.

These indications are used mainly in patients who have acute reversible renal failure. In those who have chronic renal disease greater emphasis must be placed on the clinical state which is more adversely affected than the biochemical data might indicate.

During the dialysis the biochemical state is improved. Clinical improvement is usually delayed for 24 to 48 hours. The mental state returns to normal whilst nausea and vomiting cease and the patient becomes hungry. This improvement is maintained for several days even in the absence of renal function. If severe oliguria or anuria persist then uraemia will recur and the same indi- 0 cations must be used for reassessing the optimum time to perform another dialysis.

\section{Results}

As an artificial kidney unit provides a service for a fairly large area cases that are referred for treatment are selected. Those that recover before severe uraemia occurs are not usually referred; whilst some have died in uraemia without being referred.

Table I gives the results obtained in the first I 43 patients that have been referred for treatment: I 6 were dialysed.

\section{Acute Renal Failure}

We have found it necessary to divide these into Reversible and Irreversible conditions.

\section{Reversible}

Eighty-four patients have been referred. We have divided them into three groups. The first concerned those who developed the lesion as a complication of pregnancy. Eleven were not dialysed and the remaining 22 were dialysed. Only two patients died and one of these was referred in terminal uraemia and died 30 minutes after admission. The second group concerned 32 patients who developed the lesion as a result of, or associated with trauma. Seven patients were not dialysed. Two recovered and the remaining five were all referred in terminal uraemia and died before a dialysis could be started. Twenty-five patients in this group were dialysed and only seven recovered. In those patients that died the 
TABLE 2

Daily Rise of B.U.N. in Acute Reversible Renal Failure

\begin{tabular}{|c|c|c|c|c|c|c|}
\hline : & Degree & . & $\begin{array}{c}\text { Daily rise in } \\
\text { B.U.N. (mg. \%) }\end{array}$ & No. of Patients & No. Dialysed & Recovered \\
\hline $\begin{array}{l}\text { Mild } \\
\text { Moderate } \\
\text { Severe . . }\end{array}$ & $\begin{array}{l}\ldots \\
\cdots \\
\cdots\end{array}$ & $\begin{array}{l}\cdots \\
\cdots\end{array}$ & $\begin{array}{c}<15 \\
15-30 \\
>30\end{array}$ & $\begin{array}{r}7 \\
22 \\
16\end{array}$ & $\begin{array}{r}2 \\
21 \\
16\end{array}$ & $\begin{array}{r}7 \\
20 \\
6\end{array}$ \\
\hline
\end{tabular}

uraemia had been kept under control by dialysis and all succumbed from complications, sepsis being the most frequent. The mortality in those patients who developed the lesion following major surgical procedures was high, only four of the 19 patients recovering. Four patients who were dialysed had multiple fractures and two died from fat emboli. The third group concerns i4 patients. They developed the lesion from a variety of causes such as diabetic coma, hepato-renal syndrome, poisons, drug reactions, acute symptomatic haemolytic anaemia, etc. Nine of these patients recovered but no firm conclusion can be drawn owing to the varied aetiological factors.

\section{Irreversible}

As dialysis has no permanent value in irreversible renal lesions this group must be recognised as soon as possible, dialysis being used to maintain life until an accurate diagnosis is made. Three patients had complete bilateral cortical necrosis of pregnancy. They were diagnosed during life following a percutaneous renal biopsy which was performed when renal function had not started to recover by the twenty-first day. In the remaining 17 patients acute anuria occurred without any specific antecedent episode. A retrograde pyelogram excluded a silent post-renal obstruction and the final diagnosis was made from a percutaneous or open renal biopsy.

\section{Post-Renal Obstruction}

The value of the artificial kidney in postrenal obstruction has been reviewed elsewhere (Parsons and McCracken, 1959). As these patients usually require surgical procedures it must be remembered that operative trauma increases protein catabolism which could cause serious embarrassment in a uraemic patient.

In early uraemia (blood urea less than $250 \mathrm{mg}$. per cent.) a pre-operative haemodialysis is advisable when a soft tissue $X$-ray, taken at the same time as a retrograde pyelogram, revèals diminished renal tissue. When the amount of renal tissue is normal it is probably safe to perform a nephrostomy if the blood urea is no higher than $300 \mathrm{mg}$. per cent. When renal infection is present and a major surgical procedure is required a preoperative dialysis is advisable.

In patients with obstruction of the bladder neck preliminary drainage of the bladder will indicate the state of renal function. If the uraemia is not corrected within a few days, haemodialysis should be performed; the operation being postponed until. renal function has improved.

Fourteen patients with a reversible type of postrenal obstruction have been treated and, 12 recovered. One died from a cardio-vascular catastrophy and the second died following a total cystectomy for carcinoma of bladder. Five patients were placed in the irreversible group. A retrograde pyelogram revealed the presence of a post-renal obstruction and at operation carcinomatosis was found. Four of these patients developed acute painless anuria.

\section{Miscellaneous}

A total of 20 patients have been placed in this group: 16 were dialysed. The majority presented with acute renal failure and were shown to have glomerular disease which proved to be partially reversible. Two patients developed uraemia following surgical intervention which had increased protein metabolism and overloaded the diminished renal reserve. A dialysis rapidly corrected the uraemic state and they recovered. Two patients had no renal disease. One was in diabetic coma and recovered. The other had acute hepatic necrosis but a dialysis did not affect the clinical condition and he died two days later.

\section{Metabolic Response in Acute Reversible Renal Failure}

The rate of protein catabolism in patients with acute renal failure is remarkably constant but varies considerably from patient to patient. The rate is determined mainly by the episode that precipitated the renal failure although it can be increased by complications, particularly infection. We have assessed' the rate of protein breakdown by estimating the daily rise of the B.U.N. where figures were available over a sufficient period of anuria to draw justifiable conclusions. We have divided the patients into three groups according to the rise of the B.U.N. (Table 2).

In the mild group, where the B.U.N. was rising less than $15 \mathrm{mg}$. per cent./day, dialysis was required in two patients, both having unduly protracted periods of anuria. In the moderate group, where the B.U.N: was rising between I5 
and $30 \mathrm{mg}$. per cent./day, the majority required a dialysis. In the severe group, where the B.U.N. was rising greater than $30 \mathrm{mg}$. per cent./day all required a dialysis. If it is assumed that a dialysis is required when the B.U.N. reaches $200 \mathrm{mg}$. per cent. and the B.U.N. is $30 \mathrm{mg}$. per cent. at the start of the renal failure, the day on which a dialysis is required can be calculated if the daily rise of the B.U.N. is estimated. For instance in the mild group a dialysis will be required after the eleventh day, in the moderate group a dialysis will be required between the sixth and eleventh days whereas in the severe group a dialysis will be necessary before the sixth day of anuria. The rapidity of onset of uraemia in this severe group requires a special emphasis. The B.U.N. in a patient who has received major trauma frequently rises at $50 \mathrm{mg}$. per cent./day and, applying the above calculations, we find that dialysis is required on the third day. The majority of patients in the severe group have been referred far too late. Indeed five patients (Table 2) in the trauma group of acute reversible renal failure died soon after admission and before a dialysis could be performed. Nearly all the patients in the severe group have received major trauma, either accidental or surgical, and these patients must be recognized much sooner than has been the case in the past. Any hesitation will have serious consequences for the onset of uraemia is so rapid that the optimum time to dialyse must be accurate to within 12 hours.

This classification of patients according to the rate of protein catabolism is important for other reasons:

I. Recovery Phase.-During the recovery phase renal function is impaired (Bull, Joekes and Lowe, 1949) so that correction of the uraemic state is dependant not only on urine volume but also on the rate of protein catabolism. For instance, in the mild group a 24-hour urine volume of $600 \mathrm{ml}$. is usually sufficient to correct the uraemic state. In the moderate group about $1,000 \mathrm{ml}$./day is usually sufficient whereas in the severe group an output of $\mathrm{I}, 500$ to $2,000 \mathrm{ml}$./day may be necessary. These figures are of value in deciding whether a dialysis is required in a uraemic patient when renal function is recovering.

2. Anabolic Steroids.-Any reduction in the rate of protein catabolism would naturally make the management easier, particularly in the moderate and severe groups. We have attempted to do this with 'norethandrolone (McCracken and Parsons, 1958) and testosterone (Parsons, 1959). Preliminary findings suggest that in the obstetric group $30 \mathrm{mg}$. of norethandrolone daily will reduce the urea production by 50 to 70 per cent. Testosterone appears to have less effect than norethandrolone. Little effect has been observed in other types of renal failure. The majority of patients $\frac{\omega}{7}$ in the moderate group had complications of $\varrho$ pregnancy and we anticipate that few will now $\frac{3}{D}$ require dialysis if they are treated with norethan- $\propto$ drolone from the onset of renal failure.

3. Function of Artificial Kidney.-In the future $\overrightarrow{\vec{F}}$ the majority of patients with acute renal failure requiring dialysis will be in the severe group. $\frac{}{0}$ The high rate of protein catabolism in this group $\overline{\bar{c}}$. means that dialyses are required at frequent $\widehat{\Phi}$ intervals until renal function returns. The in- $\frac{}{0}$ terval between dialyses is mainly dependant on the $s$ efficiency of the machine. We believe that the $\vec{O}$ majority of machines in current use are inadequate $\overrightarrow{-}$ to deal with these patients successfully and that a larger machine with a dialysing surface area of 2.8 to $3.2 \mathrm{sq}$. $\mathrm{m}$. with a flow rate of blood of 3 $500 \mathrm{ml} . / \mathrm{min}$. is required.

\section{Conclusions}

The artificial kidney is of most value in the management of patients with acute reversible ज renal failure and post-renal obstructions.

In patients with acute renal failure it can fresquently prolong life until renal function returnt. $z$ In the mild and moderate groups final recovery ${ }_{0}$ ? usual but in the severe group there are other facto 93 limiting recovery. Most of the patients haxe received major trauma. In 80 per cent. of ogr cases this trauma has been surgical and the rengle failure has been only one of several complications:. Only four out of 19 patients survived. Theo commonest cause of death has been sepsis but a few have died from unknown causes. We suspect $\frac{\bar{O}}{\mathrm{O}}$ that some of these might have died from nutritional depletion. Calculation reveals that these patients $\stackrel{2}{\mathbb{Q}}$ usually metabolize the same amount of protein in $\overrightarrow{\vec{P}}$ 20 days that a normal individual at rest, on a⿳亠丷厂 similar dietary regime, would metabolize in $100-5$ days. It is, therefore, not surprising that the resistance to infection is lowered and that healing of wounds is retarded. Reduction of protein 3 . catabolism in the traumatic group would materially assist in the management of these patients and 3 . would probably decrease the mortality. Untilo this ideal is attained we must insist that these $₹$ severe cases are transferred to an artificial kidneyo unit early and preferably to a centre that has $a_{\square}$ highly efficient machine.

\section{Acknowledgments}

Drs. B. H. McCracken, C. R. Blagg and O. Ciniewicz have worked with me on the artificial kidney unit and I thank them for allowingo me to use some of their records.

The Figure is reproduced by kind permission of the Editor, British Fournal of Urology.

Bibliography continued on page 639. 
thiazide is in the range of $100-200 \mathrm{mg}$. When prolonged therapy is required, supplementation of potassium intake will be required and the supplements are best given on non-diuretic days (Poznanski and Cromie, r959).

Hydroflumethiazide ('Hydrenox ')-chemically 3 : 4 - dihydro - 7 - sulphamyl - 6 - trifluoromethyl - I : $2: 4$ - benzothiadiazine - I : I dioxide, has been introduced more recently and is undergoing investigation (Hobolth et al., 1958; Sele, 1958; Kobinger and Lund, 1959). It has approximately the same potency as hydrochlorothiazide and the dosage range is similar.

Despite its frequency and in spite of much experimental study, the mechanisms responsible for hyponatraemia in chronic cardiac failure are still far from clear. There is no question, however, that some patients with intractable cardiac oedema benefit from steroid therapy (Gutner et al., 1957; Heidorn et al., 1955; Reimer, 1956; Dresdale et al., 1958). Mickerson and Swale (1959) have recently described a series of 13 patients who showed the following features in common: all had obstinate cardiac failure and had become resistant to treatment with digitalis, low-sodium diet and diuretics; they complained of excessive tiredness and increased pigmentation both of the skin and buccal mucosa was present; all showed hypo- natraemia with a normal or elevated serum potassium and a raised blood urea with one exception. All exhibited a great increase in urinary output due to a predominant water diuresis with disappearance of oedema following the addition of prednisolone, in a dose of $5 \mathrm{mg}$. t.d.s. for $24-48$ hours followed by a maintenance dosage of $2.5 \mathrm{mg}$. twice or thrice daily, to existing therapy with digitalis and diuretics and the substitution of the lowsodium intake by a normal diet.

\section{BIBLIOGRAPHY}

DRESDALE, D. T., GREENE, M. A., and GUZMAN, S. V. (1958), Amer. Heart $\mathcal{Y}$., 55, $85 \mathrm{I}$.

FLEMING, P. R., ZILVA, J. F., BAYLISS, R. I. S., and PIRKIS J. (1959), Lancet, i, 1219.

GUTNER, L. B., MOSES, J. B., DANN, S., and KUPPERMAN, H. S. (1957), Amer. Y. med. SCi., 234, 281.

HEIDERN, G. H., and SCHEMM, F. R. (1955), Ibid., 229, 621.

HOBOLTH, $N$., and THOMSEN, $K$., from HANSEN, P., HAGENSEN, N. R., and OPRESNIK,' J. (1958), Ugeskr. Laeg., 120, 1585 .

HAVARD, C. W. H., and FENTON, J. C. B. (1959), Brit. med. ₹. i, 1560 .

KERR, D. N. S., READ, A. E., and SHERLOCK, S. (1959), Lancet, i, 1221 .

KOBINGER, W., and LUND, F. J. (1959), Acta pharmacol. (Kbh.), 15,265 .

MICKERSON, J. N., and SWALE, J. (1959), Brit. med. F., i, 876. T

NORDQUIST, P., CRAMER, G., and BJORNTORP, P. (1959) Lancet, $1,271$.

POZNANSKI, W. J., and CROMIE, B. W. (1959), Brit. med. Y.

PLATTS, M. M. (1959), Ibid., i, 1565 .

REIMER, A. D. (1956), Bull. 'fohns Hopk. Hosp., 35, 728.

SELE, V.' (1958), Ugeskr. Laeg., 120, 1592.

Bibliography continued from page 624-I. H. Griffiths, F.R.C.S.

\section{BIBLIOGRAPHY}

DOS SANTOS, R., LAMAS, A. C., and CALDAS, J. (1929), Med. contemp., 47, 93.

DOSS, A. K., THOMAS, H. C., and BOND, T. B. (1942), Tex. St. Y. Med., $38,277$.

GRAVES, F. T. (1954), Brit. F. Surg., 42, 132.
HENLINE, R. B., and MOORE, S. W. (1936), Amer. F. Surg., 32, 222.

NELSON, O. A. (1942), Surg. Gymec. Obstet., 74653.

PIERCE, E. C. (1951), Ibid., 93, 56.

WHITESIDE, C. G. (1959), Personal Communication.

Bibliography continued from page 630-F. M. Parsons, B.SC., M.B., Ch.B.

\section{BIBLIOGRAPHY}

ABEL, J. J., ROWNTREE, L. G., and TURNER, B. B. (1913), Trans. Ass. Amer. Phys., 28, 51.

ALWALL, N. (1947), Acta med. scand., 128, 317.

BULL, G. M., JOEKES, A. M., and LOWE, K. G. (1949), Lancet, ii, 229.

DANZIG, L. E. (1955), New Engl. F. Med., 252, 49.

DOOLAN, P. D., WALSH, W. P., KYLE, L. H., and WISHINSKY, H. (195I), Э. Amer. med. Ass., 146, 105.

GJ $\phi$ RUP, S., and THAYSEN, J. H. (1958), Lancet, ii, 886.

KOLFF, W. J., and BERK, H. Th. J. (1944), Acta med. scand., II7, 121 .

KOLFF, W. J., and WATSCHINGER, B. (1956), F. Lab. clin. Med., $47,969$.

KYLE, L. H. JEGHERS, H., WALSH, W. P., DOOLAN, P. D., WisHINSKY, H., and PALLOTTA, A. (1953), $\}$. clin. Invest., 32, 364.
McCANCE, R. A., and WIDDOWSON, E. M. (1946), London, Her Majesty's Stationery Office.

MERRILL, J. P. (1955), 'The Treatment of Renal Failure,' Grune \& Stratton, New York and London.

MERRILL, J. P., and WELLER, J. M. (r952), Ann. Int. Med., 37, 186:

MURPHY, W. P., Jr., SWAN, R. C., WALTER, C. W., WELLER, J. M., and MERRILL, J.' P. (I952), F. Lab. clin. Med., 40, 436 .

PARSONS, F. M. (1959), Lancet, i, 148.

PARSONS, F. M., and MCCRACKEN, B. H. (1958), Brit. $\mathcal{F}$ Urol., 30, 463 .

PARSONS, F. M., and McCRACKEN, B. H. (1959), Brit. med. $\%$. i, 740.

SKEGGS, L. T., Jnr., and LEONARDS, J. R. (1948), Science, 108, 212.

WOLF, A. V., REMP, D. G., KILEY, J. E., and CURRIE, G. D. (1951), F. clin. Invest., 30, 1,062. 